\title{
Uma proposta textual frente a problemas referentes à história do átomo no ensino de química ${ }^{1}$
}

\author{
A textual proposal to face problems related to the history of the atom in \\ chemistry teaching
}

\author{
LARISSA MOREIRA FERREIRA \\ Universidade Federal de Santa Catarina | UFSC \\ LUIZ ORLANDO DE QUADRO PEDUZZI \\ Universidade Federal de Santa Catarina | UFSC
}

RESUMO O presente trabalho esboça um panorama geral da história da química no ensino brasileiro e as dificuldades que se apresentam em relação à contextualização do atomismo. Como uma possível contribuição para essa problemática, apresenta-se as características gerais de um texto que busca fazer um resgate histórico do átomo vinculado ao referencial bachelardiano, e sua avaliação por um grupo de especialistas, que mostrou as potencialidades e limitações do texto.

Palavras-chave atomismo - Bachelard - material instrucional - ensino de química.

\begin{abstract}
This paper outlines an overview of the history of chemistry in Brazilian education and the problems that arise in relation to the context of atomism. As a possible contribution to this issue, we present the general characteristics of a text that seeks to make a historical rescue of the atom, linked to Bachelardian referential and its evaluation by a group of experts, which showed the potentialities and limitations of the text.
\end{abstract}

Keywords atomism - Bachelard - instructional material - chemistry teaching.

\section{Introdução}

Frente aos problemas bem conhecidos do ensino de ciências, o governo brasileiro, através do Ministério da Educação, tem produzido documentos que visam orientar as ações de professores, a elaboração de materiais instrucionais, o conteúdo programático de currículos nas instituições de ensino etc. Os PCN (Parâmetros Curriculares para o Ensino Médio, 1999)², os PCN + (PCN + Ensino Médio: Orientações Educacionais Complementares aos Parâmetros Curriculares Nacionais, 2002) ${ }^{3}$ e, mais recentemente, as OCEM (Orientações Curriculares para o Ensino Médio, 2006) ${ }^{4}$ destacam problemas, elencam diretrizes e sugerem estratégias objetivando a melhoria do ensino e da aprendizagem em âmbito nacional. Evidentemente, o diálogo desses documentos com a pesquisa educacional é, ou deveria ser, não apenas necessário como imprescindível.

No que se refere à química, as OCEM reconhecem que a realidade escolar ainda é marcada pelo conteudismo que restringe 0 aprendizado dessa ciência à reprodução dos saberes ministrados pelo professor. Assim, destaca que um 
dos fatores de grande importância para o ensino da química deve ser o da sua contextualização sócio-histórica. Nesse sentido, recomenda 0 uso de livros paradidáticos, como $A$ ciência através dos tempos ${ }^{5}$ e de outros com contribuições à história da química.

Um fato que chama a atenção nas OCEM é o sumário desse documento. Apenas a disciplina de física possui uma subseção nomeada "história e filosofia da ciência", sendo as demais (biologia, matemática e química) desprovidas de algo similar. Mesmo reconhecendo-se a iniciativa majoritária dos físicos em se envolverem com a História e Filosofia da Ciência (HFC) ${ }^{6}$, a omissão desse conteúdo nas outras matérias, em um documento oficial, não se justifica.

No que tange às especificidades da química e da física, Michel Caillot ${ }^{7}$ aponta que as duas matérias têm relações distintas com seus saberes, de modo que "para os físicos, a inteligibilidade do mundo físico e do universo é primordial, o que coloca a pesquisa científica no coração da produção do conhecimento físico. "[...] Por outro lado, na química, a produção de conhecimentos científicos é inseparável da tecnologia, uma vez que seu objetivo é o de transformar a matéria, o que coloca em pé de igualdade a pesquisa científica e a pesquisa tecnológica"8.

Além da distinção generalizada de objetivos entre as duas ciências, o papel que elas possuem na economia e sociedade também é diferente, sendo que a química é conectada a uma indústria química forte e potente, sem contrapartida, ao menos significativa, no campo da física. Isso se traduz, entre múltiplas consequências, em proposições curriculares mais técnicas para a disciplina de química, com o propósito de atender às necessidades de pessoal qualificado para as indústrias. Tal contexto origina, de um lado, uma disciplina voltada para a "episteme", que é a física; e, de outro, uma disciplina mais voltada para a "techne", que é a química9.

A preocupação com a HFC no ensino de química é mencionada nos PCN + e consta como um item da competência que diz respeito à contextualização sociocultural. Esta, por sua vez, corresponde à inserção dos conhecimentos da química nos diferentes setores da sociedade, reconhecendo-a como parte de diferentes contextos históricos ${ }^{10}$. Já os PCN são mais enfáticos na questão da história da química, afirmando que esta deve permear todo o ensino de química, possibilitando ao aluno a compreensão do processo de elaboração desse conhecimento com seus avanços, erros e conflitos ${ }^{11}$.

A história da ciência, de modo geral, tem sido objeto de investigação por diversos pesquisadores. Uma das áreas de estudo é a de livros didáticos. No âmbito da pesquisa em ensino de química, os resultados convergem para a constatação de que esses materiais apresentam muitas insuficiências em relação à HFC. Paulo Henrique Oliveira Vidal ${ }^{12}$, por exemplo, examinou seis livros didáticos de química, todos aprovados pelo Programa Nacional do Livro Didático para o Ensino Médio (PNLEM) de 2007, tendo como foco a análise do conteúdo histórico presente nesses materiais. Entre outras conclusões, 0 autor aponta que:

- dificilmente foram encontradas descrições de aspectos da vida pessoal dos cientistas, como consequência, retirando a dimensão humana dos personagens apresentados;

- há casos onde os cientistas são apresentados como pessoas geniais, de inteligência incomum;

- há predomínio da simples menção às ideias científicas, sem tratar da sua construção histórica;

- a informação histórica apresentada nos livros didáticos é predominantemente ligeira e superficial;

- na maioria das vezes, a evolução da ciência é descrita como um processo linear e direto;

- existe elevada incidência de que a ciência é desenvolvida pelo trabalho de personagens individuais;

- os autores não utilizam fontes primárias;

- há tendência de os livros didáticos copiarem seus antecessores - muitas vezes de maneira acrítica;

- prevalece a separação entre a informação histórica e o conteúdo químico.

Romulo de Oliveira Pires e colaboradores ${ }^{13}$ examinaram criticamente, em termos históricos, livros didáticos de química do ensino médio mais utilizados por professores desse nível de ensino. Além dos livros, os autores investi- 
garam também os artigos da seção História da Química da revista Química Nova na Escola, um importante veículo de disseminação de saberes relativos a essa ciência entre professores e pesquisadores na área de ensino de química. A análise deu-se no período de 1995 até 0 ano de 2010.

Entre outras conclusões, os autores mencionam que encontraram apenas trechos relativos à vida dos cientistas, associando brevemente autores às teorias que desenvolveram, sem maior contextualização histórica. Afirmam ainda que "os livros relatam fatos histórico-científicos como se fosse algo para ocupar páginas, não permitindo que o aluno descubra o conceito através do pensamento do cientista"14. Isso acaba reforçando a noção corriqueira de que cientistas simplesmente têm insights imediatos e geniais sobre as ideias que desenvolveram. Ao mesmo tempo, essa desconexão temporal promove uma noção de obsolescência acerca de contribuições científicas passadas, ou seja, de que o que foi feito é antiquado, retrógrado e, portanto, sem valor para o contexto atual.

Embora se note alguma presença da história da ciência nos livros de química, não raro ela ocorre em boxes, em caixas laterais, desconectadas do texto. Entretanto, no que tange ao tema "atomismo", a situação é um pouco diferente: é um dos poucos assuntos onde a história consta como parte do conteúdo, do texto integral. Além disso, é frequentemente exigido em provas durante os cursos de química (tanto no âmbito do ensino médio como superior), bem como em exames vestibulares. Sua presença nos livros é detalhada a seguir.

\section{O atomismo nos livros didáticos de química}

No que diz respeito ao tópico "atomismo", o cenário é compatível com as afirmações de Hélio Elael Bonini Viana ${ }^{15}$, referentes a livros-textos de química. 0 átomo é um tema central em química, mas sua abordagem costuma ser meramente ilustrativa, com a exposição de alguns modelos atômicos ligados brevemente a seus autores e a datas, 0 que induz à noção de uma história linear.

A sequência apresentada nos livros, em geral, leva o leitor a pensar que Dalton retoma diretamente as ideias de Demócrito. Isso se verifica, por exemplo, no livro de José Carlos de Azambuja Bianchi, Carlos Henrique Albreht e Daltamir Justino Maia, aprovado pelo Programa Nacional do Livro Didático 2009/2010/2011. Conforme os autores, "embora o termo átomo fosse antigo, Dalton o retomou"16. Essa afirmação suscita indagações como: por que retomou? Por que ninguém o retomou antes? 0 que aconteceu com o conceito de átomo de Demócrito a Dalton? Que implicações tem para o ensino, no âmbito da natureza da ciência $(\mathrm{NdC})$ ? Esses e outros questionamentos são essenciais para um entendimento mais apropriado do tema.

Após as contribuições de Dalton, os livros costumam exibir brevemente os modelos atômicos de Thomson, Rutherford, Bohr, e o modelo de orbitais, (pontuado por proposições da mecânica quântica, como a dualidade onda-partícula). Não há qualquer indicação de colaboração, debates ou divergências entre os cientistas, de modo que é possível afirmar que tal descrição fomenta concepções 'deformadas' do trabalho científico conforme expostas por Daniel Gil-Pérez e

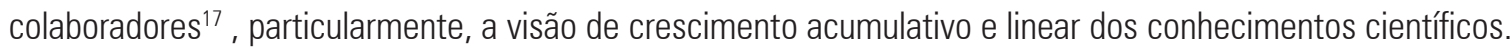

Esses problemas não são exclusividade dos livros de química do ensino médio. Viana ${ }^{18}$ analisou quatro livros de química geral amplamente utilizados no ensino superior no que diz respeito à história do atomismo, concluindo que:

Alguns erros de datas, bem como informações equivocadas, sugerem que os autores nem sempre devem ter consultado fontes adequadas para a história da ciência. É importante ressaltar que nenhum dos livros estudados menciona a importância de Newton para o desenvolvimento da teoria daltoniana. Um outro ponto a ser salientado é o fato de os livros didáticos não discutirem as conexões entre os trabalhos sobre gases do século XVIII e a teoria atômica daltoniana. Dessa maneira, as discussões referentes à primeira teoria das misturas gasosas e a regra da máxima simplicidade foram completamente esquecidas. Uma explicação plausível para essa escolha por parte dos autores é que essas ideias foram abandonadas ${ }^{19}$. 
Também os livros paradidáticos cometem equívocos. Em um episódio que se pode chamar de irônico, a própria recomendação das OCEM fomenta essa visão simplificadíssima do atomismo ao indicar o livro de Attico Chassot. Segundo este autor, "Dalton retoma a teoria proposta já há 23 séculos pelos atomistas gregos Leucipo e Demócrito"20. Chassot ainda menciona que "A teoria de Dalton ganha adeptos e há muitos avanços com os trabalhos de [diversos cientistas]", ignorando as inúmeras controvérsias e objeções das quais o átomo daltoniano foi alvo no século em que foi proposto.

As referências analisadas parecem suficientes para sustentar a conclusão de que a história do atomismo em livros didáticos é problemática no sentido de que o que é exposto é pontual e superficial. Conforme assinala Viana: "[...] os autores procuram focar as ideias que "deram certo", reforçando indiretamente a concepção de que a ciência se modifica de maneira linear e acumulativa"21. Esta observação levanta grande preocupação não só com uma história da ciência distorcida, mas também sobre a própria concepção de ciência tratada, a qual, indubitavelmente, é reflexo das concepções dos autores dos livros e que podem se propagar, negativamente por aqueles que fazem uso desses materiais: professores e alunos.

\section{Problemas, consequências e reflexões sobre a história da química no ensino}

Embora as possíveis contribuições da história e da filosofia da ciência para o ensino de ciências sejam bem documentadas na literatura científica atual, o fato é que a inserção desses conteúdos ainda não conseguiu o alcance desejável, nem na educação básica e nem em nível universitário. Conforme apontam Giulliano José Segundo Alves Pereira e André Ferrer P. Martins:

[...] a inserção da história e filosofia da ciência na educação básica e nos currículos dos cursos de licenciatura tem encontrado obstáculos. Alguns são históricos e se constituem em críticas a essa inserção, tais como: o uso de uma pseudo-história e de uma quasi-history. Outra crítica refere-se à questão da história e filosofia da ciência desfavorecer o desenvolvimento de um espírito científico nos jovens cientistas [...]. Outros obstáculos estão relacionados: à carência de material didático de qualidade, aos equívocos sobre a natureza da história da ciência e do seu uso na educação, e à falta de professores com formação específica na área em que possam ministrar as disciplinas de conteúdo histórico e filosófico [...]

Em relação a este último obstáculo [...], a inserção de disciplinas de história e filosofia da ciência nas licenciaturas fica na dependência de professores que tenham interesse e possam ministrá-las. Em estudo realizado por Rosa ${ }^{22}$, que envolveu a realização de entrevistas com vinte e um professores de duas universidades brasileiras, observou-se que somente um dos professores entrevistados apresentava formação específica na área de história e filosofia da ciência ${ }^{23}$.

Em levantamento realizado no ano de 2013, Simone Barretos Santos ${ }^{24}$ identifica que apenas uma pequena parte dos trabalhos em congressos das áreas de ensino de ciências aborda o tema da história da ciência, sendo as produções majoritariamente estabelecidas no âmbito da formação de professores. A pesquisa da autora ainda traz dados acerca da história da química em cursos de graduação do Estado da Bahia e que reforçam os dados obtidos por Rosa. Dentre os vários aspectos relatados, destacam-se: falta de formação específica dos professores que lecionam as disciplinas de história da química, grande carência de material didático, baixas expectativas dos alunos do curso pela disciplina e dificuldades de integrá-la às demais disciplinas do curso.

Embora o estudo tenha sido feito em um estado do nordeste, não seria de todo equivocado supor que o cenário apresentado é um retrato da realidade nacional e que já era similarmente descrito por João A. de M. G. Matos ${ }^{25}$ e colaboradores em 1991, como fato de a química ser considerada uma ciência de caráter bastante prático, não atribuindo 
a devida importância a aspectos de maior profundidade epistemológica, e, portanto, relegando à história da química um papel secundário, de pouca importância.

Desse modo, pode-se afirmar que a inserção dos conteúdos de história da química e sua incorporação aos currículos dos cursos de química ainda têm muito por avançar. Em alguns casos, como o da Universidade Federal de Santa Catarina, houve retrocesso, pois a disciplina lecionada na década de noventa, sobre a história da química, atualmente não é contemplada no currículo, sequer como optativa.

Um levantamento realizado por José Ramón Bertomeu-Sánchez ${ }^{26}$ em 21 países europeus acerca da presença da disciplina de história da química revela, entre outros aspectos, que, quando se trata de cursos de licenciatura em química, a disciplina de história da química é obrigatória, mas nos demais cursos é optativa. Há uma infeliz semelhança com a realidade brasileira: os professores que lecionam as disciplinas raramente possuem formação específica na área, sendo estas lecionadas por químicos da área "dura" interessados no tema.

A posição de pouco destaque da história da química é acompanhada pelo insuficiente interesse dos químicos pela filosofia da química, conforme relata Robert J. Good²7. 0 autor indica que esse desinteresse vai tanto na direção dos químicos como dos filósofos da ciência, os quais raramente se dedicaram aos problemas da química, tomando a física como ciência-modelo para suas análises, ou seja, partindo do princípio de que a ciência física corresponderia à maneira como a ciência é, ou deveria ser, de fato, feita. A grande predominância das ideias de filósofos da ciência como Thomas Kuhn, Karl Popper, Imre Lakatos ${ }^{28}$ e Paul Fayerabend em cursos de epistemologia com suas ideias pautadas predominantemente para a análise de episódios da física, ajudam a corroborar a afirmação. Um dos poucos estudiosos clássicos que se distinguem nesse sentido é Gaston Bachelard, que, embora também seja bastante conhecido e estudado, tratou de muitos temas relacionados à filosofia da química.

Nunca é demais ressaltar que, conforme Lakatos 29 , "a história da ciência sem a filosofia da ciência é cega, a filosofia da ciência sem a história da ciência é vazia". Somando-se a defasagem mútua em filosofia e história da ciência, não surpreende que livros de química sejam povoados com incoerências históricas apresentadas de maneira extremamente pontual. Ademais, como não há formação nem interesse coletivo o suficiente, a reprodução de tais ideias pelos alunos e profissionais da área também não causa espanto.

Não obstante, pesquisadores em ensino de ciências têm exposto propostas de sucesso com o uso da história da ciência em sala de aula (André Ferrer P. Martins ${ }^{30}$, Marinês Domingues Cordeiro, Giovana Teixeira Pinto e Deividi Marcio Marques, entre outros). Maria da Conceição Oki ${ }^{31}$, por exemplo, relata o trabalho em uma disciplina da história da química com alunos do curso de química, abordando questões epistemológicas, além das históricas. A autora afirma que muitas concepções simplistas e ingênuas sobre a natureza da ciência estavam presentes entre os alunos no início do curso, e que algumas delas permaneceram mesmo ao fim da disciplina. Ainda assim, Oki descreve as conquistas alcançadas: reconhecimento da historicidade do conhecimento científico e de uma maior flexibilização nos critérios de demarcação da ciência, percepção de que a credibilidade da ciência não decorre da utilização de um método científico rígido e estruturado, maior compreensão da dinâmica da atividade científica e do seu caráter coletivo.

Luiz 0. 0. Peduzzi ${ }^{32}$ afirma que a história da ciência pode, entre outros aspectos:

- Incrementar a cultura geral do aluno, admitindo-se, neste caso, que há um valor intrínseco em se compreender certos episódios fundamentais que ocorreram na história do pensamento científico [...];

- Desmistificar o método científico, dando ao aluno os subsídios necessários para que ele tenha um melhor entendimento do trabalho do cientista;

- Mostrar como o pensamento científico se modifica com o tempo, evidenciando que as teorias científicas não são "definitivas e irrevogáveis", mas objeto de constante revisão;

- Chamar a atenção para o papel de ideias metafísicas (e teológicas) no desenvolvimento de teorias científicas mais antigas; 
- Contribuir para um melhor entendimento das relações da ciência com a tecnologia, a cultura e a sociedade;

- Tornar as aulas de ciência [...] mais desafiadoras e reflexivas, permitindo o desenvolvimento do pensamento crítico;

- Propiciar o aparecimento de novas maneiras de ensinar certos conteúdos;

- Melhorar o relacionamento professor-aluno.

Portanto, os caminhos que levam a uma melhor compreensão da história da ciência no ensino de ciências já têm sido trilhados. E, embora a inserção desses conteúdos no ensino de química represente um desafio, certamente não é algo distante do possível.

\section{Buscando alternativas: o referencial histórico-epistemológico}

Dada a problemática relativa à questão do atomismo nos livros e no ensino de química e visando propiciar subsídios para um melhor entendimento desse assunto pelo professor, produziu-se, como parte de uma dissertação de mestrado, um texto de 33 páginas com uma abordagem histórica do átomo, da antiguidade ao advento do elétron. Em função do extenso período considerado e dos objetivos do texto, há limitações inevitáveis quanto à profundidade das ideias, dos conceitos tratados e de seus autores e protagonistas. De qualquer modo, as referências bibliográficas encaminham 0 leitor para leituras suplementares, nas quais ele pode encontrar o aprofundamento dos tópicos tratados.

Com esse resgate histórico, busca-se evidenciar que o átomo tem uma história, e que essa história difere substancialmente daquela que existente nos livros didáticos. A contextualização do assunto persegue o propósito de mostrar que a ciência não é uma construção linear; que há controvérsias e diferentes acepções acerca da estrutura da matéria e do conceito de átomo. Procura demonstrar que em cada época há uma filosofia hegemônica, e que, portanto, diferentes filosofias tiveram influência nas questões referentes à atomística. 0 texto, enfim, reúne elementos que têm a intenção de ressaltar que o atomismo é um tema complexo, que não pode ser devidamente tratado sem levar em conta a densa trama de aspectos conceituais, epistemológicos e ontológicos de seu desenvolvimento.

Os fundamentos epistemológicos do trabalho encontram-se em uma obra específica de Gaston Bachelard sobre 0 atomismo, intitulada Les Intuitions Atomistiques ${ }^{33}$, uma das primeiras do autor, que foi objeto de análise em outro artigo $0^{34}$.

0 trabalho de Bachelard (1881-1962) tem sido amplamente referenciado no ensino de ciências. Noções como as de "Perfil Conceitual" e "Obstáculo Epistemológico", bastante conhecidas dos educadores, têm origem no pensamento deste filósofo francês que foi professor de química e de física, e que também dedicou parte de seus estudos a entender a evolução das ciências.

Embora o foco de seu trabalho tenha sido a epistemologia, o aspecto educacional esteve bastante presente em sua obra. Foi crítico do ensino dogmático promovido pelos livros didáticos e da suprema autoridade do professor. Outro fato apontado por ele foi o pouco espaço concedido à história das ideias científicas. Além disso, Bachelard considera a experimentação com o intuito de chamar a atenção do aluno, cheia de efeitos marcantes, como falsos centros de interesse, sugerindo que "o professor passe continuamente da mesa de experiências para a loufsa, a fim de extrair 0 mais depressa possível o abstrato do concreto" ${ }^{\prime 35}$ Bachelard não poupa nem o gênero literário de ficção científica, cujas obras acusa de serem verdadeiras regressões infantis, as quais podem ser divertidas, mas nunca instrutivas.

No que tange às suas preocupações históricas que nortearam as suas proposições epistemológicas, Bulcão ${ }^{36}$ faz as seguintes considerações: 
- Bachelard opõe-se à concepção positivista da época, ou seja, o simples relato das descobertas feitas no passado pelos cientistas, em progresso contínuo, introduzindo a noção de ruptura. Esta, por sua vez, preconiza que a ciência progride por retificações de erros e por reorganizações do saber que rompem inteiramente com as teorias passadas;

- Para Bachelard, a história precisa ser julgada, pois não teria sentido simplesmente descrever os fatos sem uma crítica que mostre o fundamento e a validade das descobertas científicas;

- Pelo mesmo princípio mencionado anteriormente, a história precisa ser recorrente, ou seja, é necessário que se analise os fatos científicos do passado a partir da ciência atual a fim de que se tenha a possibilidade de compreender melhor a evolução e a superação das dificuldades da ciência anterior.

Les Intuitions Atomistiques traz à luz as filosofias influentes nas concepções científicas acerca do conceito de átomo. Para a estruturação e desenvolvimento do texto Atomismo: um resgate histórico, elaborado pelos autores deste trabalho, selecionou-se aquelas que se julgou mais apropriadas para os fins didáticos do mesmo: 0 atomismo realista, 0 atomismo positivista e 0 atomismo axiomático. As demais (atomismo criticista e "a metafísica da poeira"), face a sua maior complexidade e ao caráter introdutório do material instrucional, não foram abordadas

\section{Sobre a constituição do texto}

0 texto Atomismo: um resgate histórico ${ }^{37}$ está dividido em seis seções, precedidas por uma introdução e seguidas de considerações gerais.

A Introdução contempla a forma como em geral o atomismo é retratado nos livros-textos, questionamentos que levaram ao desenvolvimento do material, preocupações da legislação educacional com a história da ciência e os objetivos do texto, que procuram enfatizar que:

1. O átomo tem uma história, e que essa história é muito distinta da que é contada nos livros didáticos;

2. A ciência não é uma construção linear-que há controvérsias e diferentes acepções acerca da estrutura da matéria e do conceito de átomo;

3. Em cada época existe uma filosofia hegemônica, e que diferentes filosofias tiveram grande influência nas questões referentes à atomística;

4. O atomismo é uma matéria complexa e profunda, e que não pode ser abordado de forma tão superficial, como geralmente ocorre nos livros didáticos e no contexto escolar.

Na seção 0 princípio da teoria atômica: antiguidade resgata-se os primórdios da teoria atômica, seus fundamentos, primeiros pensadores e teorias divergentes para a constituição da matéria. Discorrendo-se sobre o porquê da florescência intelectual na Grécia antiga, passa-se às ideias de Leucipo, Demócrito e Epicuro de que a matéria é constituída por átomos, explicando a concepção de mundo subjacente a esse conceito.

Em contraste, apresentam-se as ideias de Aristóteles, que, partidário da teoria dos quatro elementos e do éter, opõe-se ao vazio, sustentando que a matéria é contínua, ou seja, que pode ser infinitamente divisível. Nessa perspectiva, explora-se o debate entre a continuidade/descontinuidade da matéria, a existência ou não do vazio, e a ideia de um Criador, entre outros temas. 0 antagonismo entre pensadores constitui-se em um dos propósitos basilares do texto, que procura deixar claro que os conceitos não têm aceitação instantânea nem homogênea, e que divergências e embates fazem parte da elaboração conceitual pela qual passa o conhecimento. Isso, certamente, contrasta com o modo imediatista, pontual e sem conflitos como é apresentada a história do átomo nos livros didáticos. 
No segmento seguinte 0 átomo no contexto medieval e outras teorias para a estrutura da matéria, correspondente ao período da Idade Média, objetiva-se mostrar a visão ocidental, sob a influência da Igreja Católica, sobre o tema. Assim, são examinados os posicionamentos da Igreja frente ao atomismo, mais especificamente sobre a rejeição ao epicurismo como um todo e o modo como o átomo fica intrinsecamente ligado a Epicuro e atrelado aos demais aspectos de seu pensamento. Em oposição, as ideias de Aristóteles foram bem aceitas a partir da sua 'cristianização' por São Tomás de Aquino. A predileção pelas ideias aristotélicas é exemplificada por meio da caracterização feita por Dante na sua Divina Comédia, que mostra Aristóteles adulado no Paraíso enquanto Epicuro arde no Inferno.

Abordam-se, também, as primeiras frustradas tentativas de conciliação do atomismo com os preceitos da Igreja, bem como as incursões dos alquimistas na busca de outras teorias para explicar a composição da matéria.

A fim de pontuar filosoficamente esse segmento da trajetória histórica, trata-se do aspecto realista dessas primeiras proposições para a estrutura da matéria de acordo com as reflexões de Bachelard. Mais especificamente, fala-se do realismo ingênuo que floresce na tentativa de explicar um fenômeno a partir de suas propriedades. Isso, na teoria atômica, é exemplificado pela explicação de que uma superfície é áspera por conter átomos pontudos. Assim, a qualidade de ser áspero não está na mão de quem toca, nem da composição dos átomos, nem de qualquer outro fator exterior, e sim no próprio átomo.

Dando prosseguimento ao texto, a seção Tentativas de cristianização do átomo: polêmicas com a igreja católica discute a hipótese atômica no contexto de abertura científica e cultural promovido pelo Renascimento. Destaca-se, em particular, o trabalho de Pierre Gassendi, que tentou reabilitar a filosofia epicurista a fim de conciliá-la com o pensamento cristão e foi crítico da filosofia aristotélica.

Galileu Galilei e Giordano Bruno são, igualmente, referências relevantes na contextualização do assunto. 0 primeiro, por sua suposta relação oculta com o atomismo e a hipótese de que tenha sido condenado à prisão domiciliar não por seus estudos astronômicos, mas sim por endossar o atomismo e as ideias de Epicuro. 0 segundo, Giordano Bruno, por ser um atomista entusiasta, embora acreditasse que entre um átomo e outro houvesse éter. Apesar de sua crença em Deus, manifestou uma espécie de panteísmo pessoal, questionando alguns dogmas da lgreja, como o conceito de pecado original. Tudo isso o colocou em rota de colisão com a Igreja, sendo acusado de heresia e pagando pelos seus "pecados" com a vida.

Um marco histórico importante do período foram os experimentos de Evangelista Torricelli sobre o vazio e a pressão atmosférica. Juntamente com os de outros estudiosos, eles foram seminais para a rejeição da máxima aristotélica de que "a natureza tem horror ao vazio".

0 segmento $A$ queda dos elementos de Aristóteles e o nascimento da química quantitativa, compreendendo 0 período dos séculos XVII e XVIII, apresenta o estado da ciência química e as primeiras tentativas de demonstrar experimentalmente que o mundo é composto de corpúsculos. A prática química que se desenvolvera até esse período é marcada por muitos resultados sobre reações e tipos de compostos. No entanto, uma teoria amplamente consensual, que explicasse tamanha diversidade de dados não havia ainda sido encontrada, de modo que cada químico mantinha concepções e pressupostos teóricos próprios.

Um dos personagens do período é Isaac Newton, que, além de ter deixado contribuições marcantes e bem conhecidas à ciência, também desenvolveu uma teoria corpuscular. Embora falha, ela representou uma séria tentativa de demonstrar a existência dos constituintes fundamentais da matéria.

Outro estudioso mencionado por suas ideias atomísticas é o químico Robert Boyle, cujas contribuições incluem a legitimação da ciência química, segregando-a da alquimia e introduzindo um método experimental rigoroso. Boyle também apresentou uma definição clara de "elemento", e mostrou experimentalmente que nem os quatro elementos de Aristóteles, nem os três princípios dos alquimistas (enxofre, mercúrio e sal) são elementos. No entanto, as investidas no sentido de obter evidências de que o mundo era feito de átomos não prosperaram e, para muitos, o átomo não passava de uma mera hipótese. 
As contribuições de Antoine Laurent de Lavoisier também são abordadas, pela sua importância não só para a química, mas também para a edificação da consolidação do atomismo científico, posteriormente, no século XIX. Entre seus bem-sucedidos esforços de refutar a teoria do flogístico, ele realizou a decomposição da água que, assim, não podia mais ser considerada como um 'elemento'.

Suas investigações o levaram, inclusive, a propor uma definição de elemento que representou um avanço em relação às de seus predecessores: "[...] todas as substâncias que não foram ainda decompostas por nenhuma maneira, consideramos elementos" ${ }^{\prime 38}$. 0 estabelecimento da lei da conservação da matéria associada à demonstração da importância dos estudos gravimétricos na estrutura da matéria é outro notável legado de Lavoisier à ciência.

Na seção seguinte Início da era do atomismo científico: proposições, confrontos e teorias alternativas, correspondente ao século XIX, expõem-se as ideias atomísticas de Dalton, bem como a repercussão que elas tiveram à sua época e os entraves à sua aceitação, que foram muitos. Isso ocorreu por numerosos motivos, entre eles o fato de que a teoria atômica conforme proposta por Dalton era composta por proposições a priori, como o fato de que os elementos químicos combinavam-se entre si por proporções definidas. Tal suposição levou à determinação errônea de fórmulas químicas de substâncias como a água, teorizada por Dalton como sendo HO e que o colocou em conflito com seu contemporâneo Louis Joseph Gay-Lussac, cujos dados divergiam e não podiam ser conciliados com a teoria de Dalton.

Esse conflito, entre outros no período, gerou percepções sobre o átomo segundo três visões principais:

\section{Os que aceitavam o átomo como realidade física material;}

2. Os que rejeitavam o átomo como realidade física material;

3. Os que rejeitavam o átomo como realidade física material, mas que o consideravam como uma explicação útil para determinados fenômenos. Neste caso, o átomo não é concebido como uma entidade real, mas como um modelo.

Além de um exame mais detalhado dessas perspectivas, são abordadas as teorias concorrentes ao atomismo, como a química-matemática, a teoria dos átomos turbilhão e as explicações fornecidas pelo energetismo de Friedrich Wilhelm Ostwald. Apesar dos obstáculos, as evidências que corroboravam a existência dos átomos começavam a se acumular: Lei de Dulong-Petit, Lei de Raoult, Lei de Avogadro, os trabalhos de Jean Perrin na determinação do número de Avogadro e a matematização do movimento browniano por Albert Einstein.

0 aporte bachelardiano é utilizado então para mostrar ao leitor a influência da filosofia positivista sobre a aceitação de um conceito científico. De acordo com Bachelard, uma boa maneira de descrever o positivismo seria a de que ele preconiza que a ciência é uma construção de fatos, somente pelos fatos. Assim, teorias e especulações sobre a origem e funcionamento dos fenômenos não seriam científicas na medida em que demandariam atividades para além do que pode ser imediatamente detectável e observável.

Na penúltima parte do texto, denominada 0 átomo existe. E tem tomos são discutidas as consequências da consolidação do átomo como ente fundamental da matéria, e o advento de sua primeira partícula: 0 elétron, produto de uma série de experimentos e de concepções sobre a estrutura da matéria geradas por vários cientistas, inclusive, de diferentes nacionalidades. A identificação do elétron não foi, portanto, súbita e individual. Essas asserções, entre outras, são fundamentais para que se desmistifique a imagem do cientista isolado e genial, que cria teorias repentinas por experimentos singulares.

0 elétron abriu caminho para que fossem encontradas outras partículas, como o próton e o nêutron. A partir desses avanços, foi possível compreender a estrutura do átomo, mecanismos de reações químicas e a posição dos elementos na tabela periódica, além de fomentar o desenvolvimento da mecânica quântica. Nesse sentido, segundo Bachelard, o átomo passa a ser um axioma. 0 termo "axioma" remete a uma noção de "ponto de partida", de onde se admite determinado fato a fim de que se possam deduzir suas consequências. Um exemplo disso é a imagem da fenomenologia do gás sendo ionizado, a qual está intrinsecamente ligada à imagem do elétron e do átomo. Implica também no fato 
de que a ciência atômica moderna está sob a dependência do pensamento técnico, e não da experiência comum, de modo que uma experiência particular é a própria materialização de um teorema.

Encerra-se o texto com as Considerações finais, mencionando-se que o texto procurou fazer um resgate histórico do átomo que contemplasse não só a história do atomismo em si, mas que permitisse também compreender como ela se transformou dentro do contexto no qual estava inserido: concepções de mundo, de religião, de filosofia e de ciência influenciaram fortemente a maneira como se utilizou e se concebeu 0 átomo através dos tempos. E ainda, que com o texto se espera contribuir para subsidiar as ações do professor de química interessado em levar o conhecimento histórico a seus alunos, no âmbito do atomismo.

\section{Delineamento da pesquisa}

Considerando o caráter inovador do texto Atomismo: um resgate histórico, optou-se por sondar as suas potencialidades junto a especialistas, isto é, entre acadêmicos envolvidos com o ensino de química e já familiarizados com a história e epistemologia da ciência. Apesar da formação específica nessa área ser desejável, não foi julgada um critério indispensável, considerando-se relevante a conhecida atuação dos sujeitos em disciplinas relacionadas ao tema.

A investigação compreende um estudo de caso, caracterizado por Augusto N. S. Triviños como "uma categoria de pesquisa cujo objeto é uma unidade que se analisa aprofundadamente" ${ }^{\prime \prime 3}$.

Para a avaliação do texto elaborou-se um questionário constituído por seis perguntas abertas, dissertativas. Com esse tipo de instrumento, busca-se uma maior elaboração das opiniões do entrevistado, que assim não se limita a assinalar, ou atribuir seu grau de concordância ou discordância às alternativas previamente selecionadas pelo pesquisador ${ }^{40}$.

Quanto à forma escolhida para o envio do questionário, fez-se a opção por "Questionário por Correio", na qual 0 indivíduo responde às questões formuladas sem a presença do entrevistador ${ }^{41}$. Uma "versão" deste procedimento é denominada "Questionário por Correio Eletrônico", ou seja, via e-mail, dada a praticidade e a economia de tempo e recursos que essa tecnologia permite em comparação com o correio convencional.

As questões versaram sobre os seguintes tópicos: adequação da contextualização histórica, relevância dos aspectos filosóficos, conexão entre aspectos históricos e filosóficos, pertinência dos conteúdos, clareza da linguagem.

Com o propósito de verificar o efetivo potencial do instrumento para a avaliação do material instrucional, para fins de validação, procedeu-se a uma análise preliminar do mesmo. Assim, encaminhou-se o texto e o questionário, via correio eletrônico, a três acadêmicos. Apesar de todos terem concordado em participar da pesquisa, apenas dois responderam. A análise das respostas evidenciou que o questionário apresentou-se bastante satisfatório em relação à clareza de seus itens, não sendo visíveis erros de interpretação ou qualquer outro tipo de problema no enunciado das questões. Sendo assim, não houve razão para fazer alterações nas perguntas elaboradas e nem incluir novos itens.

0 questionário foi enviado a 27 acadêmicos. Dez professores e/ou estudantes de pós-graduação, pertencentes a várias instituições de ensino (UFRN, UFSC, FURG e UFBA), o responderam, ficando a amostra assim constituída:

A1 - Licenciando em Química (integrante de um Programa Institucional de Bolsa de Iniciação à Docência e familiarizado com o tema investigado);

A2 - Químico Doutorando em Ensino de Ciências;

A3 - Químico Doutor em Química;

A4 - Químico Mestre em Educação em Ciências;

A5 - Químico Mestre em Ensino de Ciências Naturais e Matemática; 
A6 - Químico Doutor em Química;

A7 - Químico Pós-Doutor em Filosofia da Ciência;

A8 - Química Doutoranda em Ensino, Filosofia e História das Ciências;

A9 - Químico Doutor em Psicologia;

A10 - Químico Doutorando em Educação em Ciências.

As respostas às perguntas formuladas são analisadas a seguir, por questão e individualmente. Na última seção, faz-se uma discussão mais geral e integradora dos resultados encontrados.

\section{Avaliação do material instrucional}

QUESTÃO 1 - A história exposta no texto visa mostrar as diferentes faces que o atomismo adquiriu através dos tempos, contrapondo-se à lacuna histórica de Demócrito a Dalton existente nos livros didáticos. 0 texto cumpre esse objetivo? 0 aprofundamento dado aos episódios históricos relatados é adequado?

A maioria dos participantes concorda que o texto cumpre os seus objetivos e dá aprofundamento adequado às questões. Enquanto A3 e A7 limitaram-se a dizer que sim, outros acadêmicos fizeram considerações mais completas. Para A1, o "texto mostra as diversas faces do atomismo" mostrando um aprofundamento significativo uma vez que discute aspectos filosóficos que fundamentaram cada uma das concepções de átomos. Já A4 acredita que o texto cumpre o objetivo de "explicar" a referida lacuna no momento em que, de modo cronológico, conta e explica o percurso atomístico Demócrito-Dalton. Afirma que o aprofundamento teórico é adequado, que há uma série de episódios históricos de que não tinha conhecimento e sugere que seja criado um esquema, organizado de forma cronológica, com pequenos textos, pois acredita que seria mais didático em uma inserção no Ensino Médio.

A5 diz que deveria ser dado um tratamento mais aprofundado às importantes controvérsias envolvendo 0 atomismo no século XIX, principalmente à proposta energetista, que a seu ver poderia ser mais bem trabalhada. Assim, sugere acrescentar uma breve discussão das contribuições para a resolução deste debate no século XIX, mencionando a importância do congresso de Karlsruhe em 1860, e qual o papel da comunidade científica e de um evento como esse no processo de produção do conhecimento científico, já que o texto está sendo pensado para professores.

A8 acredita que o texto cumpre o objetivo específico de cobrir a lacuna histórica presente não só no discurso de vários professores como também nos manuais didáticos, que apresentam o período da Idade Média como um grande vazio teórico. Aponta que o texto apresenta um aprofundamento histórico adequado, sem cometer 0 erro de ser simplista e anacrônico. Declara que o texto evidencia que a ciência é uma produção coletiva, de natureza não linear e não acumulativa.

Segundo A10, o texto é muito interessante, pois retrata episódios passados em vários séculos, não somente a respeito da teoria atômica, mas também relativos à própria história da ciência. Diz que os fatos históricos escolhidos na composição do texto são muito pertinentes, mencionando que a maioria dos livros didáticos propõe uma visão generalizante e linear da produção de conhecimento no que tange à teoria atômica.

A2, A6 e A9, acreditam que as metas do texto foram atingidas apenas parcialmente. 0 primeiro pondera que 0 texto alongou-se demais no período da Grécia Antiga, e pouco nos restantes. De qualquer modo, considera o texto "longo demais". Já A6, afirma que falta profundidade aos episódios tratados, de modo que pensa que o texto cumpre apenas parcialmente o objetivo proposto ao informar que a noção de átomo foi sendo utilizada ao longo do tempo. Esperava que 0 texto discutisse mais os diversos conceitos de átomo - ao invés de simplesmente constatar sua permanência - apontando as mudanças e procurando explicá-las. 
0 participante A9 elabora uma resposta bastante extensa, de aproximadamente duas páginas e meia. Os pontos principais incluem a percepção do texto como uma interessante apresentação de fatos históricos do atomismo, embora considere várias insuficiências. Nessa perspectiva, afirma haver carência de variedade de referências e propõe a inserção de diversos episódios históricos que não foram tratados no texto, como a ascensão de Demóstenes, a queima de livros em Alexandria, o congresso de Karlsruhe, entre outros.

De fato, em um texto com pouco mais de trinta páginas são inevitáveis os recortes. Ainda que profundidade e extensão não sejam sinônimos, não raro andam juntas, pois o aprofundamento de qualquer questão exige o pormenor da discussão e a pluralidade de pontos de vista. No extenso período histórico considerado há muitos conceitos, episódios e personagens envolvidos, e em qualquer abordagem, mesmo em livros, como os de Bernard Pullman ${ }^{42}$ e Juergen Maar ${ }^{43}$, que foram referências para o desenvolvimento do texto, haverá sempre uma simplificação de conteúdos.

0 que é possível concluir a partir das respostas é que o texto toca em uma lacuna histórica importante nos manuais didáticos, e que pode, no mínimo, ser um bom ponto de partida para subsidiar discussões mais aprofundadas em torno do atomismo.

QUESTÃO 2 - 0 texto faz vínculos entre a abordagem histórica do atomismo e a epistemologia de Bachelard, mencionando também as filosofias hegemônicas que, segundo este autor, influenciaram as concepções científicas ao longo do tempo. A relação entre a história apresentada e o referencial epistemológico é apropriada?

A1, A3, A8 e A10 acreditam que o texto cumpriu a contento o objetivo. A3 foi econômico nas palavras e declarou um simples "sim". Outros participantes fizeram considerações mais específicas.

Segundo A1, a relação é apropriada, uma vez que no texto são expostos, explicados e exemplificados conceitos da teoria de Bachelard; isso permite ao leitor um fácil entendimento, ainda que não tenha conhecimentos sobre este autor. A8 afirma que, por alguns momentos, elementos da epistemologia bachelardiana são trazidos ao texto para fornecer um sustentáculo gnosiológico à construção do conhecimento químico dentro do contexto atômico, e por isso pensa que o referencial epistemológico é satisfatório.

0 participante A10 considera que a proposta do texto, ancorada essencialmente em Bachelard, é muito interessante uma vez que proporciona compreender os aspectos sócio-históricos da produção de conhecimento a respeito da teoria atômica.

Porém, outros participantes apontaram insuficiências com base em seus conhecimentos de outras obras e ideias de Bachelard. A5, embora considere a relação apropriada, sugere citar ao longo do texto e do contexto histórico em discussão "qual tipo de obstáculo epistemológico está sendo tratado, na ótica bachelardiana". 0 participante A2 também concorda que a relação é adequada, mas afirma que o texto deixa lacunas em pontos que Bachelard denota como importantes, como o papel na mudança de paradigma. Para A9, o texto apresenta muito poucas referências à obra de Bachelard e ao seu próprio texto acerca do atomismo. Alega que há pelo menos dois conceitos importantes que não foram contemplados no texto: a fenomenotécnica e a cidadela científica, conceitos para os quais aponta referências.

Para A4, o referencial epistemológico evidencia a "descontinuidade" e afirma ser difícil dar uma definição da adequação do texto ao referencial teórico devido ao fato de que fez poucas leituras das obras de Bachelard.

Já A6 respondeu negativamente à questão, afirmando, entre outras assertivas, que, a seu ver, o tratamento filosófico do texto ficou pouco claro e portanto poderia ser mais discutido. Ressalta que a escolha por Bachelard não Ihe pareceu adequada, pois este não é um autor fácil para se iniciar na filosofia da ciência.

0 participante A7 afirmou que acha importante apoiar-se nas ideias de Bachelard e sugere outras referências sobre o realismo.

É oportuno ressaltar que, apesar das noções de ruptura, obstáculos epistemológicos e fenomenotécnica serem seminais na filosofia bachelardiana elas não foram explicitamente consideradas porque a obra de Bachelard sobre 0 
atomismo - uma das primeiras do autor, e referência para o desenvolvimento do texto - não contempla esses conceitos. De todo modo, a incorporação desses conceitos em uma articulação do texto com outros materiais e obras de Bachelard pode ser feita pelo professor devidamente capacitado e interessado em aprofundar o tema.

QUESTÃO 3 - Entre outros propósitos, o texto tem a finalidade de apresentar uma história pensada, ou seja, uma história que possibilite ao professor a percepção de que aspectos referentes à natureza da ciência são inerentes ao próprio desenvolvimento de conceitos científicos. 0 texto alcança este objetivo?

Dos participantes, A2, A6 e A9 discordam do cumprimento desse objetivo. 0 primeiro acredita que isso não fica evidente declarando que "tem que deixar bem mais claro, mais direto". Já A6 reporta-se à resposta dada na questão dois, pontuando que a discussão sobre a natureza da ciência não é boa. 0 participante $A 9$ remonta à questão um, alegando que há lacunas históricas, e que a forma do texto a seu ver é inadequada: muito afirmativa e pouco reflexiva e interpretativa.

Efetivamente, o texto não dá destaques do tipo "observe a relação aqui entre a filosofia da época e a ciência produzida", pois o seu formato não enseja este tipo de ligação. Sem dúvida, isso seria mais apropriado com o vínculo do texto a um roteiro de estudos, por exemplo.

Segundo A1, o texto deixa claro que o desenvolvimento científico não é "solto"; que todo conhecimento é gerado à luz de um contexto. A7 considera que se buscou "rechear" um período histórico negligenciado e que isso foi feito com competência. No entanto, questiona: o professor de química daria conta de transitar por esses caminhos? É uma pergunta interessante e que indica a percepção de que o professor de química, em geral, não possui formação suficiente para fazer discussões de cunho histórico-epistemológico. Por esse motivo, certas modificações no material instrucional, como as sugeridas pelos participantes (explicitadas a seguir), devem ser objetos de uma reflexão (e algumas certamente implementadas) para que o professor, até mesmo sem uma formação sólida na área, possa ter uma melhor compreensão do tema e fazer uso do mesmo.

0 participante A8 afirma que o texto apresenta uma lógica de construção que revela os bastidores da química e que o professor, ao ler o material "não apenas se deparará com os produtos desta Ciência, mas fundamentalmente com os elementos constitutivos desta". 0 participante A10 respondeu de forma similar, colocando que o texto alcança o objetivo de contribuir para o entendimento de que a ciência é construída sócio-historicamente, bem como tem 0 potencial para ressignificar sentidos dados aos processos educativos tanto por alunos como professores, de modo que isso implica também produção de sentidos nas histórias de vida destes sujeitos.

A3, A4 e A5, sucintamente, também concordaram que o texto atinge seus objetivos no que tange à natureza da ciência e sua relação com o desenvolvimento científico.

QUESTÃO 4 - 0 texto é adequado para subsidiar os estudos do professor sobre o assunto, com o objetivo de levar este conteúdo para a sala de aula do professor em Ensino Superior, Ensino Médio ou ambos?

À exceção de A2 e A9, a utilização do texto é considerada adequada pelos demais participantes em ambos os níveis de ensino. A1 afirma que "[...] o texto serve de subsídio para aprofundar os conhecimentos tanto para 0 ensino médio como para o ensino superior". Apesar de concordar quanto à adequação, outros acadêmicos fizeram ressalvas.

Enquanto A3 julga o texto suficiente para o Ensino Médio, A4, A5, A7, A8 e A10 o consideram excessivamente aprofundado nesse nível.

A4 e A5 levantam pontos interessantes. Para A4, o texto é adequado para a utilização em sala de aula do Ensino Superior, mas para o Ensino Médio deveria ser construído na forma de esquemas (tabela, linha de tempo, com imagens e textos curtos), pois da maneira atual pode ser maçante para o Ensino Médio. Além disso, alega não haver tempo de ser trabalhado na sua totalidade segundo a carga horária disponível. A5 faz apontamentos similares, sugerindo a implementação de recursos como quadros, tabelas, esquemas, mapas, entre outros. 
Já A6 afirma que, apesar do potencial para utilização, há o problema da falta de clareza do aspecto epistemológico, que poderia ser superado se o professor que usar o texto tiver algum domínio de epistemologia da química, complementando-0.

A2 declara que não usaria o texto nem no Ensino Médio nem no Ensino Superior, pois o classifica como muito longo e linear, com redação pouco atrativa. Considera que o texto precisaria ser mais claro - embora não diga onde - e que deveria mostrar os objetivos que pretende atingir em cada etapa da história. Para um texto já 'longo' como ele ressalta, essa última sugestão, para não ser contraditória, demandaria uma ligação do texto com um guia ou roteiro de estudos.

Além de afirmar que haveria dificuldade de utilização do texto no ensino médio, A7 ressalta que, no ensino superior, seu uso seria condicionado ao interesse do professor pela história e filosofia da ciência ou que tenha sido formado nessa perspectiva, embora acredite que esses conteúdos acabem sempre sacrificados. Acrescenta ainda que "sempre é complicado acrescentar algo a mais ao professor". Apesar disso, acredita que o material é uma boa fonte de apoio para o tema.

0 participante A9 não responde diretamente à questão, apenas opina que o texto é um interessante esboço e que precisaria ser extensamente revisado, principalmente em relação aos próprios fatos históricos que ele buscaria narrar. Critica a ausência de imagens no texto e afirma que faltam os nomes completos e outras referências biográficas (como época de vida e nacionalidade, por exemplo) dos personagens históricos envolvidos na narrativa.

Quanto a sugestões relativas à inserção de recursos didáticos mais "atraentes" ao texto, como boxes, imagens e esquemas, é necessário ficar atento para que tais iniciativas não se sobreponham ao conteúdo. Embora esses acréscimos possam parecer de fato mais aprazíveis ao jovem leitor, é necessário cautela para o texto não se configure em um "falso centro de interesse" 44 , fugindo aos objetivos do mesmo.

\section{QUESTÃO 5 - A abordagem linguística e argumentativa utilizada no texto é clara e acessível para o professor?}

Os participantes $A 1, A 3, A 4$ e $A 7$ responderam positivamente à pergunta, sem estender-se nos comentários. A5 acredita que a abordagem linguística é clara e acessível, mas complementa: "Se for o professor da educação básica, talvez 0 texto precisasse passar por uma revisão para o esclarecimento de alguns termos comumente utilizados no âmbito acadêmico, tais como epistemologia, a-histórico, dentre outros." Assim, ele não sugere substituir os termos, mas elucidá-los a fim de que o professor se aproprie desses novos conceitos.

A8 afirma que a linguagem do texto é clara, mas que o leitor sem conhecimento sobre Bachelard pode ter dificuldades em alguns pontos da leitura. A10 faz asserção similar e complementa que seria interessante, ao término de cada parte, retomar o argumento central pois estes contribuiriam para uma compreensão mais satisfatória do texto.

A2 indica que certos termos precisam ser melhor esclarecidos e conceitos desenvolvidos, como, por exemplo, "epistemlogia" e "química moderna". Acrescenta que o texto dá "a ideia de que a história da humanidade é linear, numa sequência cronológica de fatos quase positivista". Sem dúvida, a orientação epistemológica conferida ao desenvolvimento histórico do atomismo contrasta com a sequência "quase positivista" dos conteúdos vista por A2. Ainda que não se tenha claro em que sentido $\mathrm{A} 2$ tenha usado o termo, é difícil entender crítica tão contundente, pois a história positivista não contempla discussões do teor das que foram feitas.

Os participantes A6, A8 e A9 ressaltaram a necessidade de realizar pequenas correções gramaticais ao texto, que, em geral, foi considerado bem escrito.

QUESTÃO 6 - Como professor, você utilizaria o texto proposto, ou parte dele, para trabalhar o tema do atomismo com seus alunos? Em caso positivo/afirmativo, que referências e/ou metodologias de ensino você associaria ao texto?

À exceção dos participantes A2 e A9, os demais afirmaram que utilizariam o texto em sua prática pedagógica. É importante destacar a variedade de metodologias sugeridas pelos participantes: seminários (A4), debates (A3 e A5), 
estudos dirigidos (A6 e A8), contextualização de uma situação atual (A10), rodas de formação (A4), problematização (A1). Cabe frisar que as propostas foram distintas umas das outras. Isso sinaliza para a versatilidade do texto, para a multiplicidade de maneiras com que pode ser usado, oportunizando ao professor adaptá-lo à metodologia que considera mais adequada a seus alunos.

0 acadêmico A2 justifica sua recusa com o argumento de que os alunos do Ensino Médio não teriam "a menor paciência" para lê-lo. Além disso, acredita que: "o texto poderia discutir controvérsias atuais da ciência [...] e voltar ao passado para mostrar como o conhecimento científico se desenvolve. Ou mostrar que a ciência não é neutra e é influenciada por fatores sociais, econômicos, culturais, políticos, etc., o texto não permite vislumbrar isso, parece que tudo ocorre só no mundo isolado dos cientistas".

Efetivamente, o texto é voltado para subsidiar as discussões do professor sobre um tema cuja transposição didática, promovida pelos manuais didáticos, é insuficiente do ponto de vista conceitual, histórico e epistemológico.

0 respondente $\mathrm{A} 7$ não deixa sugestões, apenas indica a leitura de comentários feitos ao longo do texto, sendo que alguns consistem na indicação de referências bibliográficas.

0 participante A9 afirma dispor de conhecimentos suficientes para uma abordagem histórica do atomismo, não considerando necessária a utilização de mais uma referência à sua prática docente.

0 respondente $\mathrm{A} 10$ faz uma exposição bastante prolongada e rica em reflexões (de aproximadamente três páginas) da metodologia que utilizaria, que incluiu o desenvolvimento de uma unidade de aprendizagem pautada em usinas nucleares, a partir da qual surgiriam questionamentos que levariam aos estudos realizados pelo casal Curie, radioatividade, estrutura atômica e a história do átomo. Destaca a importância dessas discussões nos processos de formação de professores e enfatiza o papel da história da química na potencialização para o (re)pensar sobre os processos sócio-históricos de produção do conhecimento.

Houve ainda um item denominado "Comentários gerais, críticas e sugestões sobre o texto" onde os entrevistados puderam se posicionar mais livremente.

A2, A7 e A8 não fizeram comentários. A1 considera o texto "realmente muito bom", fazendo sugestões de modificações ortográficas pontuais. A4 e A5 voltaram a ressaltar a importância de adicionar recursos complementares dentro do texto. A6 sugere "identificar os conceitos de átomo empregados ao longo do tempo e os fenômenos que permitiram explicar suas limitações", além de indicar referências bibliográficas. A9 alegou não haver tempo suficiente para refletir mais sobre a proposta do texto. A10 reitera que 0 texto certamente potencializará discussões, problematizações e diálogos acerca da natureza epistemológica do átomo tanto para professores como alunos.

A3 afirma ter achado a escolha pelo tema interessante, mas acredita que os "átomos pertencem naturalmente a Física, pois o químico se interessa principalmente por moléculas, ou seja, pela reação entre átomos e/ou entre átomos e moléculas e/ou entre moléculas". Esse comentário, de certa forma, reforça o que foi mencionado anteriormente no tocante tanto à história do atomismo como protagonista de uma secessão entre químicos e físicos quanto às considerações a respeito do estado atual da história e filosofia da química. Os químicos parecem afastados do alicerce de sua ciência, de modo que essa reaproximação deve ser parte dos objetivos perseguidos pela educação em química.

\section{Considerações finais}

0 texto Atomismo: um resgate histórico procura oferecer subsídios ao professor de química, em especial, para que ele possa reconhecer e lidar com as insuficiências históricas do atomismo nos livros didáticos. Evidentemente, 0 material não tem pretensões de esgotar o tema. 
A avaliação do texto por especialistas mostrou suas potencialidades e limitações. Certamente, muitas das críticas e sugestões apresentadas poderiam ter sido melhor elucidadas com uma entrevista após o processo de análise do questionário. Como isso não foi feito, certas respostas podem e devem ser consideradas com parcimônia e à luz dos objetivos delineados no início da pesquisa. Por exemplo, há certas críticas contundentes à discussão epistemológica do texto, classificando-a como superficial. Mas deve-se observar que o texto nunca teve o propósito de aprofundar-se nesse âmbito nem de servir como única referência sobre os assuntos tratados.

Do mesmo modo, dificilmente se pode ver o texto como uma construção linear, dada a contextualização dos assuntos e do seu aporte bachelardiano. Ele representa uma tentativa de edificar uma concepção menos simplista da história do atomismo, trazendo a essa compreensão aspectos sócio-culturais e científicos que influenciaram no desenvolvimento do atomismo ao longo do tempo e na desconstrução do átomo como unidade indivisível da matéria. As referências vinculadas ao texto, além de fundamentarem a sua composição, cumprem também o papel de encaminhar 0 leitor interessado a leituras adicionais para 0 aprofundamento dos temas abordados.

Várias críticas, observações e sugestões mostraram-se úteis para o aperfeiçoamento do texto. Assim, em uma nova versão, pretende-se, entre outros pontos/aspectos, inserir algumas imagens e mapas cartográficos; incluir o episódio histórico do Congresso de Karlsruhe; incorporar um glossário com alguns termos e conceitos que se apresentaram de mais difícil compreensão e anexar um índice de referências bibliográficas organizado por temática de interesse.

Algumas recomendações extrapolaram os próprios limites do texto, sinalizando a necessidade da otimização e complemento de seus conteúdos com metodologias que enfatizem, entre outras estratégias, o papel do professor (bem formado), com conhecimentos capazes de suscitar o interesse e o espírito crítico de seu aluno.

Os resultados da avaliação do texto pelos especialistas indicam que ele não pode ser trabalhado isoladamente, e sim como parte de um arcabouço metodológico que englobe estratégias como as que foram por eles sugeridas. Nessa perspectiva, para um público-alvo que não tem muitos conhecimentos prévios do assunto, a mera entrega e leitura não ensejam, ou dificultam, ao menos, a reconstrução histórica e conceitual que se almeja com o material.

Quanto aos aspectos positivos do texto, a se julgar pelos comentários de uma fração majoritária dos participantes, pode-se destacar que ele pode contribuir para:

- Desmistificar a noção de "ressureição" do conceito de átomo de Demócrito por Dalton, conforme exposto nos livros didáticos;

- Introduzir o leitor a aspectos sobre a natureza da ciência

- Subsidiar estudos acerca da história do atomismo, tanto no Ensino Médio como no Ensino Superior, com a devida transposição didática;

- Servir como ponto de partida para estudos mais aprofundados em história e filosofia da ciência;

- Fomentar o senso crítico quanto a passagens históricas excessivamente simplistas e visões ingênuas sobre a natureza da ciência em materiais instrucionais.

- Difundir ideias de Bachelard relevantes ao ensino de ciências.

Com as devidas ressalvas feitas pelos respondentes, algumas de muita pertinência, pode-se afirmar que 0 texto pode ser utilizado, tanto na formação inicial quanto na formação continuada de professores. 0 seu uso na formação inicial seria, provavelmente, mais desafiador, visto que nem todas as instituições de ensino possuem disciplinas sobre a história da química na sua grade curricular. Mesmo assim, o texto poderia se integrado a certas disciplinas da licenciatura como "Metodologia para o Ensino de Química", "Instrumentação para o Ensino de Química" e outras disciplinas afins. Nesse caso, no entanto, o bacharelando em química estaria, em princípio, excluído, a menos que houvesse um engajamento do estudante em procurar esses conhecimentos e/ou do próprio curso em encontrar meios de oferecê-los em espaços adequados. 
Em relação à formação continuada, sua aplicação ficaria condicionada aos objetivos do curso de aperfeiçoamento, ao perfil do grupo de participante e à formação do professor formador. 0 mesmo pode ser dito em relação a cursos de pós-graduação.

0 texto representa uma tentativa de oferecer ao professor um material alternativo para o ensino do atomismo. Nesse sentido, vai ao encontro do que recomendam os documentos oficiais e à pesquisa em ensino de ciências, quanto a preencher uma lacuna ainda grande no que se refere à disponibilidade de materiais relativos ao tema e fundamentados histórica e epistemologicamente. Mesmo não sendo uma tarefa fácil, iniciativas como essa são viáveis.

A crítica construtiva é essencial e parte integrante da pesquisa que visa a melhoria do ensino.

\section{Notas e referências bibliográficas}

Larissa Moreira Ferreira é doutoranda no Programa de Pós-Graduação em Química e professora da Universidade Federal de Santa Catarina.

E-mail: larissamf@outlook.com.

Luiz Orlando de Quadro Peduzzi é doutor em Educação e professor da Universidade Federal de Santa Catarina. E-mail: luizpeduzzi@gmail.com.

1 Os autores agradecem aos professores que gentilmente aceitaram participar da pesquisa e aos árbitros pelas valiosas contribuições para o aperfeiçoamento do artigo.

2 BRASIL. Ministério da Educação. Secretaria da Educação Média e Tecnológica. Parâmetros Curriculares Nacionais: Ensino Médio. Brasília: Ministério da Educação, 1999.

3 BRASIL. Secretaria de Educação Média e Tecnológica. PCN+ Ensino Médio: Orientações Educacionais Complementares aos Parâmetros Curriculares Nacionais. Ciências Da Natureza, Matemática e Suas Tecnologias. Brasília: MEC, SEMTEC, 2002.

4 BRASIL. Secretaria de Educação Básica. Orientações curriculares para o ensino médio. Brasília: Ministério da Educação, 2006, v. 2.

5 CHASSOT, Attico. A ciência através dos tempos. São Paulo: Moderna, 1994.

6 GOOD, Robert J. Why are Chemists 'Turned Off' by Philosophy of Science? Foundations of Chemistry, 1999, p.66-95

7 CAILLOT, Michel. La théorie de la transposition didactique est-elle transposable? In C. Raisky et M. Caillot (Eds), Au-delà des didactiques, le didactique. Paris: De Boeck, 1996, p. 19-35.

$8 \quad$ CAILLOT, op. cit., 1996, p. 12

$9 \quad$ Idem.

10 BRASIL. Secretaria de Educação Média e Tecnológica, op. cit. 2002, p. 92.

11 BRASIL. Secretaria de Educação Média e Tecnológica, op. cit. 1999, p.31.

12 VIDAL, Paulo Henrique Oliveira. A história da ciência nos livros didáticos de química do PNLEM 2007. 2009. 104 f. Dissertação (Mestrado) - Universidade de São Paulo, São Paulo, 2009.

13 PIRES, Romulo de Oliveira; ABREU, Thais Costa de; MESSEDER, Jorge Cardoso. Proposta de ensino de química com uma abordagem contextualizada através da história da ciência. Ciência em Tela, v. 3, n. 1, p.1-10, 2010.

14 PIRES, op. cit. 2010, p. 6.

15 VIANA, Hélio Elael Bonini. A construção da teoria atômica de Dalton como estudo de caso - e algumas reflexões para o ensino de química. 106 f. Dissertação (Mestrado) - Universidade de São Paulo, São Paulo, 2007.

16 BIANCHI, José Carlos Azambuja; ALBREHT, Carlos Henrique; MAIA, Daltamir Justino. Universo da Química. São Paulo: FTD, 2005, p. 78.

17 GIL-PÉREZ, Daniel., et al. Para uma imagem não deformada do trabalho científico. Ciência \& Educação, Bauru, v. 7, n. 2, p. 125-153, 2001.

18 VIANA, op. cit., 2007. p. 62.

19 Idem, p. 80.

20 CHASSOT, op. cit., 1994. p.188.

21 VIANA, op. cit., 2007. p.80.

22 ROSA, Katemari Diogo da. A Inserção de história e filosofia da ciência na formação de professores de física: a experiencia da UFBA e da UFRGS. $198 f .2006$. Dissertação (Mestrado em Ensino, Filosofia e História da Ciências) - Instituto de Física, Universidade Federal da Bahia, Salvador.

23 PEREIRA, José Segundo Alves; MARTINS, André Ferrer. A inserção de disciplinas de conteúdo histórico-filosófico no currículo dos cursos de licenciatura em física e em química da UFRN: uma análise comparativa, Caderno Brasileiro de Ensino de Física, v. 28, n. 1, 2011, p. 234.

24 SANTOS, Simone Barretos. A história da química como disciplina: um estudo dos cursos de licenciatura em química das universidades do estado da Bahia. 2013. 165 f. Dissertação (Mestrado) - Universidade Estadual do Sudoeste da Bahia, 2013.

25 MATOS, João A. de M. G. et al. Ensino de Disciplinas de história da química em Cursos de Graduação. Química Nova, v. 4, n. 14, p. $295-295,1991$. p.295. 